\title{
The effects of cultural background on patient-perceived impact of psoriatic arthritis - a qualitative study conducted in Brazil and France
}

Penélope Esther Palominos ${ }^{1,2^{*}}$ (D), Laure Gossec ${ }^{3}$, Sarah Kreis $^{3}$, César Luis Hinckel ${ }^{4}$, Rafael Mendonça da Silva Chakr ${ }^{1,2,4}$, Ana Laura Didonet Moro', Willemina Campbel| ${ }^{5}$, Maarten de Wit ${ }^{6}$, Niti Goel ${ }^{7}$, Charles Lubianca Kohem ${ }^{1,4}$ and Ricardo Machado Xavier ${ }^{1,2,4}$

\begin{abstract}
Background: In psoriatic arthritis (PSA) almost all qualitative studies have been performed in European populations. This work aimed to evaluate the impact of PsA in Brazilian and French subjects, as well as to explore cultural differences in the experience of disease and to recognize domains important for patients living with PsA outside Europe.

Methods: A qualitative study was conducted in two university hospitals in Brazil and France; outpatients fulfilling Classification Criteria for PsA participated in individual interviews regarding the impact of PsA; interviews were conducted in the local language. The sample size was defined by saturation; interviews were recorded and transcribed and content analysis was performed.
\end{abstract}

Results: Fifteen patients were interviewed in Brazil and 13 in France. Mean disease duration was $16.5 \pm 12.5$ years (range: 8 months to 47 years) and $14.4 \pm 8.4$ years (range 12 months to 29 years) for Brazilian and French subjects, respectively. A broad impact was perceived: 67 codes emerged from the interviews and were grouped in 41 categories. Although 2/3 of categories were common to both nationalities, some important health domains from the perspective of PsA patients from a non-European background were brought to light including sexual dysfunction, emotional impact of psoriasis and impact of prejudice on social and professional life.

Conclusions: This study highlights the importance of assessing the impact of PsA on a national level, emphasizing the common cross-cultural aspects but also revealing domains of interest for patients with PsA living outside Europe which merit further study.

Keywords: Psoriatic arthritis, Quality of life, Qualitative research, Disease burden

\section{Background}

Psoriatic arthritis (PsA) is a chronic rheumatic disease leading to altered quality of life, pain and functional disability, but also professional and emotional burden [1-5]. Perceptions of the impact of PsA differ between patients and physicians, with patients usually indicating

\footnotetext{
* Correspondence: penelopepalominos@gmail.com

${ }^{1}$ Serviço de Reumatologia, Hospital de Clínicas de Porto Alegre, Ramiro Barcelos Street 2350, Porto Alegre Zip code 90035903, Brazil

2Programa de Pós Graduação em Ciências Médicas, Universidade Federal do Rio Grande do Sul (UFRGS), Ramiro Barcelos 2400, Porto Alegre Zip code 90035903, Brazil

Full list of author information is available at the end of the article
}

a greater life impact compared to health professionals and describing aspects of impact which physicians may not acknowledge [6]. In this regard, qualitative studies are useful to obtain patients' opinions about the impact of disease.

Using qualitative methods to support the recognition of the most affected domains of health according to European patients, a questionnaire to evaluate patientperceived impact of disease, the PsA Impact of Disease Questionnaire (PsAID) was recently developed [7].

(C) The Author(s). 2018 Open Access This article is distributed under the terms of the Creative Commons Attribution 4.0 International License (http://creativecommons.org/licenses/by/4.0/), which permits unrestricted use, distribution, and reproduction in any medium, provided you give appropriate credit to the original author(s) and the source, provide a link to the Creative Commons license, and indicate if changes were made. The Creative Commons Public Domain Dedication waiver (http://creativecommons.org/publicdomain/zero/1.0/) applies to the data made available in this article, unless otherwise stated. 
Qualitative methodology was also employed to verify if the questionnaires currently available to assess PsA include concepts important to patients [8].

A recent systematic literature review (SLR) analyzed the effects of PsA reported by patients in 13 qualitative studies and categorized them by a standardized reference system, the International Classification of Functioning, Disability and Health (ICF). The ICF component most represented was activities and participation (42.6\%) rather than body structures $(10.3 \%)$ or body functions (29.4\%), indicating that the social impact of disease is very important for people living with PsA [9].

The impact of PsA from the patients' perspective has been well studied in European patients and to date, published qualitative studies in PsA have included patients mostly from Eastern and Western European countries $[7,8,10-16]$. Data on PsA impact are scarce for patients from countries outside of Europe.

In rheumatoid arthritis (RA) and systemic lupus erythematosus (SLE), it has been demonstrated, that even in the same country, distinct ethnic groups present different perceptions about the rheumatic disease and therapy [17-19]. In addition, RA patients from different nationalities have different priorities when attending a rheumatologic visit [20]. We can hypothesize that patients with PsA living in different countries would also present different perceptions on the impact of PsA.

Quantitative studies have indicated Brazilian patients with PsA have an impaired quality of life and suboptimal control of disease activity but qualitative studies aiming to obtain the patient-perceived impact of PsA in Brazil are lacking $[21,22]$. Given the differences between Europe and the ethnic (diverse ethnicity), cultural, religious (diverse religious groups but mainly Catholic) and economic background of Brazil, it is of interest to explore potential similarities and differences in patient perceptions of disease. Indeed, since most patients prefer to be involved in decisions concerning PsA and its treatment, a better understanding on the impact of disease from the patients' perspective can lead physicians to optimize assessment of PsA and to facilitate shared decision-making [23].

The main objective of the present work was to evaluate the impact of PsA in Brazilian and French patients using a qualitative methodology. We also aimed to explore cultural differences in the experience of disease in Brazil and France and to recognize domains important to patients living with PsA outside the European background.

\section{Methods}

A qualitative study with individual interviews was conducted in two public academic tertiary hospitals: Hospital de Clínicas de Porto Alegre, in Porto Alegre, Brazil and Pitié-Salpêtrière Hospital, in Paris, France. The sample comprised outpatients fulfilling the Classification Criteria for PsA (CASPAR) able and willing to participate in a $1 \mathrm{~h}$ interview in the local language (Portuguese or French) [24]. In each country, the selection of participants aimed to ensure a broad spectrum of demographic aspects and different degrees of disease severity and manifestations through purposeful sampling.

Patients with a concomitant rheumatic disease other than PsA and patients not fluent in the local language were excluded [15].

The sample size was defined by saturation, i.e., the point when two consecutive interviews did not reveal additional concepts and the researcher obtained enough information about the subject [25]. New participants were interviewed until saturation was reached in each country.

\section{Quantitative data collection}

Demographic characteristics and data about PsA were collected by the patient and the interviewer (using the medical file when necessary) before the interview: age, gender, professional status, educational level, ethnicity, current medication, extent of skin disease, presence of joint deformities, functional assessment measured by the Health Assessment Questionnaire (HAQ), and patient assessment of pain, skin and global disease on a 0 $100 \mathrm{~mm}$ visual analogue scale [26]. These data were not used as outcome measures but allowed the description of the patient sample.

\section{Qualitative interview}

Questions used in the interview were developed by the authors, with input from patient research partners of the Group for Research and Assessment of Psoriasis and Psoriatic Arthritis (GRAPPA) [27]. The semi-structured interview had three main questions: the first one was an open question which directly identified domains of health affected in PsA, "What is the impact of PsA on your life?". The additional questions encouraged patients to describe domains not routinely assessed by their health professionals and domains in which they expected improvement with therapy: "Is there any aspect of PsA that is important to you but is not often evaluated by doctors?", and "What do you expect from an effective treatment for PsA?". In addition, patients were encouraged to express themselves through prompt questions like: "Can you give us an example?", "What is your opinion about that?", "What do you do in these occasions?", "Could you talk more about that?"

\section{Data analysis}

In Brazil, the interviews were conducted in Portuguese by the first author (PEP) and recorded using Audacity version 
2.1.2. In France, the interviews were conducted by two investigators (SK and LG) and recorded by audiotape.

Interviews were transcribed and analyzed in the original language using the qualitative content analysis method [28].

First, two researchers independently read the transcripts to gain a contextualized impression of the interview. Then, codes were assigned to each sentence of the interview by each researcher independently, a process called coding. A code is a word or short phrase that captures and summarizes what the patient says in a particular part of the interview. In the sentences "I can't dress myself, tie my shoelaces and buttons due to psoriatic arthritis" and "Now I can't walk outdoors on flat ground and climb up steps", for example, the codes "dressing" and "walking" could be used, respectively, to summarize the sentences.

The codes were created directly from data, without any preconceived ideas or theories. After coding the interview independently, the two researchers met to refine the codes: findings were shared, discussed and agreed by the two coders.

Then, codes were clustered together according to similarity and regularity creating categories. Category is a group of codes which share the same characteristics. In the previous example, the codes "dressing" and "walking" could be included inside the category "functional disability".

Codes and categories were then reviewed by a third researcher and disagreements were solved by consensus among the three investigators.

Interviews from Brazil were coded in Portuguese Language by PEP and RMSC and codes and categories reviewed by CLK. All three researchers were native Portuguese speakers. Interviews from France were coded in French Language by PEP and ALNM. Both researchers were fluent in the French Language but since they were not native French speakers, codes and categories were reviewed by LG, a native French researcher.

Categories were classified in three groups: those that were common to Brazil and France, those referred only by Brazilian participants and those referred only by French participants. The final interpretation of data was done by the first author (PEP - Brazilian researcher) and the second author (LG - French researcher) and reported in a descriptive manner using the English Language. This language was chosen since it was a common language to the six co-authors involved in the coding process and to the three patient research partners from GRAPPA who contributed to the project. The final reporting of results was finally read and agreed by all the six coders and patient research partners.

\section{Results}

Twenty-eight PsA patients were interviewed: 15 in Brazil and 13 in France. The individual demographic data and disease characteristics of participants are described in Table 1. A comparison between the French and Brazilian samples is shown in Table 2. The samples from Brazil and France had participants with a wide range of disease duration, including patients with early PsA to those with more than 20 years of diagnosis. Brazilian patients had higher disease activity, a higher proportion of participants with current or previous use of biological therapy and a lower educational level compared to the French sample (Table 2).

The analysis of the 28 transcripts found 67 different codes, grouped in 41 categories. Twenty-seven out of 41 categories (66\%) were common to Brazilian and French participants (Table 3).

\section{The physical impact of PsA}

Eleven categories represented the physical impact of PsA (27\% of the total 41 categories) and 6 of these (55\%) were common to Brazilian and French participants (Table 3).

Pain was viewed as a disabling, intense and unremitting symptom by both nationalities, with participants usually describing an inflammatory rhythm associated with PsA pain: "the pain is worse in the morning, and everything is difficult, getting on and off the bus... Then, after work and movement, you feel better but I have pain all the time, you end up learning to live with it" (Male, 38 years old, Brazilian).

Functional disability, with impairment in motion, hygiene/ dressing and use of hands was widely cited in both samples. Patients expressed that PsA affected their ability to walk, run, go up and down stairs, get in and out of the car and use public transportation: "It is really difficult to walk, to sit down and get up off a chair is hard, to go to the bathroom is hard, to get up from the bed is hard, to go down stairs to go to the subway is exhausting" (Female, 37 years old, French).

Other activities such as washing oneself, tying shoelaces, putting on and taking off clothes, showering, and lowering/raising the toilet seat were also limited due to PsA. The involvement of hands was viewed as an obstacle to daily living activities such as picking up and carrying objects, opening and closing water taps, opening cans, cutting meat, cooking, handling cutlery, sweeping, washing clothes and peeling fruits and vegetables. "Before the treatment I could not hold the fork and knife anymore. I was invited to dinner by people who were not very close to me and it really makes me sad to say that I didn't eat because I couldn't cut my meat!" (Female, 67 years old, French). "The situation had reached a point where I could not take off my clothes, take a shower, put on a coat or a jacket, tie my shoes, it was unbearable" (Male, 19 years old, French). The code "loss of independence" due to functional disability emerged in both samples. 


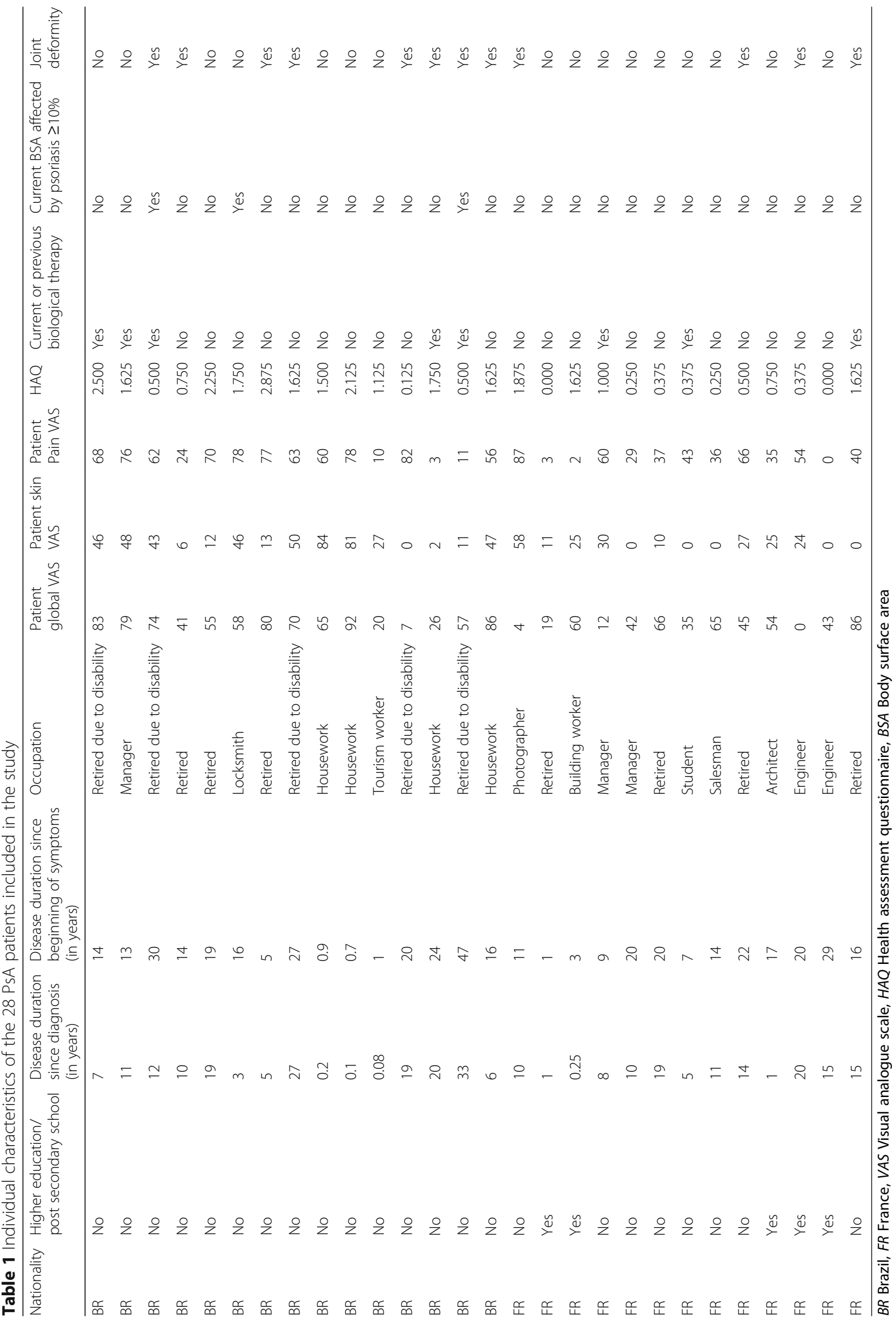


Table 2 Comparison of demographic characteristics and disease activity of patients interviewed in Brazil and France

\begin{tabular}{|c|c|c|}
\hline & Brazil $(N=15)$ & France $(N=13)$ \\
\hline Age (in years), Mean $\pm S D$, range & $51 \pm 11,28-70$ & $54 \pm 17,19-81$ \\
\hline Female sex N (\%) & $8(53.3)$ & $6(46.1)$ \\
\hline Mean PsA duration since diagnosis (in years) $\pm S D$, range & $11.4 \pm 10.0,10$ months to 33 years & $9.5 \pm 6.7,3$ months to 20 years \\
\hline Mean PSA duration since beginning of symptoms (in years) $\pm S D$, range & $16.5 \pm 12.5,8$ months to 47 years & $14.4 \pm 8.4,1$ to 29 years \\
\hline Educational level: patients with higher education (university level) N (\%) & $0(0.0)$ & $5(38.5)$ \\
\hline Currently exerting professional activity N (\%) & $7(46.6)$ & $4(30.8)$ \\
\hline Current or previous use of biological therapy N (\%) & $5(33.3)$ & $3(23.0)$ \\
\hline Current BSA involved by psoriasis > 10\% N (\%) & $3(20.0)$ & $0(0.0)$ \\
\hline Patients with joint deformities N (\%) & $8(53.3)$ & $4(30.7)$ \\
\hline Patient global VAS (0-100 $\mathrm{mm})$ Mean $\pm S D$, range & $54 \pm 27,7-92$ & $40 \pm 26,0-86$ \\
\hline Patient skin VAS (0-100 mm) Mean $\pm S D$, range & $34 \pm 26,0-84$ & $16 \pm 17,0-58$ \\
\hline Patient pain VAS $(0-100 \mathrm{~mm})$ Mean $\pm S D$, range & $55 \pm 27,3-82$ & $37 \pm 25,0-87$ \\
\hline \multicolumn{3}{|l|}{ Disability measures by $\mathrm{HAQ}$} \\
\hline Mild (HAQ 0-1) N (\%) & $4(26.7)$ & $10(76.9)$ \\
\hline Moderate (HAQ > 1-2) N (\%) & $7(46.4)$ & $3(23.0)$ \\
\hline Severe $(\mathrm{HAQ}>2-3) \mathrm{N}(\%)$ & $4(26.7)$ & $0(0.0)$ \\
\hline
\end{tabular}

SD Standard deviation, N Number, PSA Psoriatic arthritis, BSA Body surface area, VAS Visual analogue scale, HAQ Health assessment questionnaire

Table 3 Impact of PsA: comparison of categories found in Brazil and France

\begin{tabular}{|c|c|c|c|}
\hline & Brazil & Common Categories & France \\
\hline Physical Impact & $\begin{array}{l}\text { Weight gain/loss } \\
\text { Joint swelling } \\
\text { Joint deformities } \\
\text { Sexual dysfunction }\end{array}$ & $\begin{array}{l}\text { Pain } \\
\text { Fatigue } \\
\text { Functional disability } \\
\text { Sleep disorders } \\
\text { Psoriasis } \\
\text { Joint stiffness }\end{array}$ & Uveitis \\
\hline Emotional Impact & Embarrassment/Shame & $\begin{array}{l}\text { Anxiety } \\
\text { Frustration } \\
\text { Fear } \\
\text { Lack of interest } \\
\text { Depressed mood } \\
\text { Low self esteem } \\
\text { Irritability }\end{array}$ & Poor concentration \\
\hline Professional Impact & Discrimination at work & $\begin{array}{l}\text { Inability to perform job-related activities } \\
\text { Absenteeism/job losses } \\
\text { PsA symptoms impaired by occupational } \\
\text { activity } \\
\text { Financial impact } \\
\text { Low productivity } \\
\text { Inability to work full-time } \\
\text { Necessity to delegate tasks and/or ask } \\
\text { for other people's help }\end{array}$ & $\begin{array}{l}\text { Difficulties to create a long term } \\
\text { career plan } \\
\text { Necessity to change position in company } \\
\text { Necessity to change occupational activity } \\
\text { Difficulties to get a job } \\
\text { PsA impairing career advancement }\end{array}$ \\
\hline Social Impact & Discrimination in social life & $\begin{array}{l}\text { Patient perception of harming relatives } \\
\text { Incomprehension of disability by relatives } \\
\text { Limited activities with younger relatives } \\
\text { Limitation to children's care } \\
\text { Limitation to leisure activities } \\
\text { Limitation to sports } \\
\text { Sports impairing PsA symptoms }\end{array}$ & \\
\hline
\end{tabular}


Besides pain and functional disability, other categories were common to Brazilian and French patients: "fatigue", "joint stiffness", "sleep disorders" and "psoriasis/ skin impact". Fatigue seemed very important to patients and they usually described the fatigue of PsA as being more intense than "normal" fatigue, e.g., the tiredness which occur in healthy subjects after exercise or an intense day of work.

Since $20 \%$ of the Brazilian patients had more than $10 \%$ percent of body surface area covered by psoriasis, it appears this influenced the identification of more codes representing the characteristics of skin lesions (e.g., itching, burning, bleeding, scaling, fissures) and the consequences of psoriasis (e.g. psoriasis impairing sleep, discrimination due to skin lesions) in this sample.

Other categories of physical impact were described: Brazilian participants referenced "joint swelling", "joint deformities", "sexual dysfunction" and "weight gain/loss" while "uveitis" was cited by French patients.

The category "sexual dysfunction" was classified inside the domain "physical impact" because, in the opinion of participants, the effects of psoriasis on physical appearance was responsible for the decreased libido and decline in sexual activity, although the code "decreased libido" could also be viewed as an emotional impact of disease.

The increase in body weight was perceived by Brazilian patients as a consequence of restricted physical activity due to PsA and the use of corticosteroids, while lack of appetite and weight loss were perceived as consequences of medicines used to treat PsA.

\section{The emotional impact of PsA}

Nine categories of emotional impact were found in this study (22\% of the total 41 categories) and 7 (78\%) of those categories representing emotional impact were common to Brazilian and French participants.

Besides common categories as "anxiety", "low selfesteem", "frustration", "irritability", "fear", "lack of interest" and "depressed mood", the category "embarrassment/ shame" emerged in the Brazilian sample. The emotional impact of skin disease and the reporting of situations in which prejudice was experienced were repeatedly cited by Brazilians: "If you are waiting in a line, the person behind or the person in front of you looks at you, and takes a step to the side not to be too close. I think the prejudice is visible" (Male, 42 years old, Brazilian). "... in the crowded bus, the people were squeezed together standing, but no one sat next to me ... when I missed a medical visit, doctors said I could not miss it, but no one knew what I was feeling going there, taking the bus, suffering because of the prejudice, I got to the point that I took money from other things to buy gas and go to the clinic by car" (Female, 64 years old, Brazilian).
It was interesting that while the category "low self-esteem" for the Brazilian sample was mainly related to the prejudice and psoriasis, the same category in French subjects was more associated with functional disability: "I could not drive anymore, it was difficult to move around; it affects your self-esteem and the emotional side" (Male, 75 years old, French). "I felt different from others around me. This disease affects your self-esteem. I am 30 years married and my husband is a very good person to me. We lived many months without an intimate relationship due to the skin lesions" (Female, 54 years old, Brazilian).

Patients from both nationalities considered that the loss of independence due to pain and disability were contributing factors to depressed mood. Furthermore, the Brazilian patients perceived their depressed mood being driven primarily by the negative thoughts that other people had about them due to psoriasis.

\section{The professional impact of PsA}

Thirteen categories revealed the professional impact of PsA and represented $32 \%$ of the total number of categories in this study. Seven out of 13 (54\%) were common to both nationalities (Table 3): "inability to perform job-related activities", "absenteeism/job loss", "PsA symptoms impaired by occupational activity", "financial impact", "low productivity", "inability to work full-time" and "necessity to delegate tasks and/or ask for other people's help".

Activities which involved the use of hands, heavy load lifting, immobility over long periods of time, major physical efforts and the obligatory wearing of high heels on the job were some examples of tasks impaired by PsA: "Some things I used to do, I can't do anymore; I went on rooftops using a ladder. But when you are using a ladder and fixing the roof, you must stand 10-15 minutes in the same position and I feel tired" (Male, 42 years old, Brazilian). "One year ago, the pain was so present and so permanent that I had to reject proposals. I could not accept more work because I was not able to work several hours in a day. My projects were put on hold because I could not work a whole day on the keyboard due to the pain in my hands" (Male, 33 years old, French).

Participants reported adapting their occupational activity, delegating tasks, slowing down the rhythm of work, adapting objects and tasks and even changing their occupation: "I used to work alone doing iron gates and grids but now I don't have strength in my wrists and I have to ask for other peoples' help. This is something that makes me sad because it's my business" (Male, 42 years old, Brazilian).

\section{The social impact of PsA}

Eight categories of social impact were found (20\% of the total 41 categories) and 7 of these $(87 \%)$ were common to Brazilian and French participants (Table 3). 
Regarding family life, patients from both countries referenced having limited their leisure activities with children and grandchildren because they were not able to play and practice sports with them. The ability to take care of infants and newborns was perceived as impaired and participants reported they were afraid of dropping the babies and not being able to prevent accidents.

Participants reported that their relatives were not able to understand disability and pain caused by PsA: "It is difficult for other people to accept that you are sick. I try to look normal in the workplace; for three-quarters of the day it is as if nothing was wrong. When I get home, I am exhausted. And so, my husband doesn't accept it. He says: I don't understand, during the day you seem well and then, without any reason, when you're home you're tired and weak" (Female, 48 years old, French). "... in your social or family life it is not always simple because when you have pain you are not in the mood to do things, and not everyone understands it." (Male, 19 years old, French).

Brazilian and French patients reported limited participation in physical activities and sports, e.g., walking, football, running, volleyball, water aerobics, ski, biking, rowing and tennis. Pain, joint stiffness, functional disability and depressed mood were domains limiting leisure activities in both nationalities. Patients reported avoiding the beach and swimming pool due to psoriasis and refusing long trips due to pain and stiffness caused by extended periods of immobility. Dancing, going to parties, playing musical instruments, cooking, visiting friends and family, going out to dinner, swimming, diving and travelling by bus were some examples of leisure activities impaired by functional disability. Besides avoiding some activities, patients referenced that some leisure activities had to be adapted, e.g. replacing a beach trip by a city trip, visiting only one place instead of multiple places in the same day, slowing down the pace of activities.

\section{Discussion}

This study brings new and important information on patient-perceived impact of PsA and for the first time addresses cross-cultural similarities and differences in this regard. This qualitative study confirmed the broad impact perceived by PsA patients both in Brazil and in France: 41 categories emerged from the interviews, covering physical, emotional, professional and social domains. There were both similarities and differences between perceptions in Brazil and in France: 2/3 of categories were common to both nationalities in spite of cultural and economic differences between the countries, as well as variances between the public health systems. However, some important health domains from the perspective of PsA patients from a non-European background were revealed including sexual dysfunction, emotional impact of psoriasis and impact of prejudice on social and professional life.

This study has strengths and weaknesses: the Brazilian sample of this study was recruited in the most southern state of Brazil, a region characterized by European colonization with a predominance of Caucasian inhabitants. Since Brazil is a large country with a multicultural population, we can hypothesize that the impact of PsA could be different if patients from other regions were interviewed. In France, the sample was ethnically representative but in both countries, the recruitment of Black and Asian patients was difficult because they are minorities among the population of patients attending the tertiary health centers which recruited participants to the study. Education levels were high, mainly in the sample from France, which is often the case in qualitative studies [29]. The characteristics of the sample may limit generalizability.

However, patient sampling did strive for a wide spread of patient characteristics. And rather than to obtain generalizability, this methodology intends to create new hypotheses that should be consequently tested in quantitative studies. The sample size was small but saturation was reached which strengthens our results. Content analyses were performed in an undirected way thus leading to both known aspects of impact, and some new aspects. Although this study is limited by the small sample size, rigorous data interpretation methods were applied and comparisons were performed with the literature. Thus, this qualitative study allowed a first exploration of patients' experiences of impact of PsA in South America, and we believe some important insights have been gained.

The present study found a wide diversity of health domains affected by PsA, thus confirming previous studies but including information on individuals from a different cultural background [30-32]. The impact of PsA is not only physical (the aspect most easily recognized by health professionals) but it is also psychological and social. Most domains perceived as important for the patients interviewed in our work were also highlighted in other studies and are covered by questionnaires assessing impact and quality of life in PsA $[4,7,8,32]$. Fatigue, functional disability, social participation and emotional impact, for example, are assessed by the PsAID, the Psoriatic Arthritis Quality of Life (PsAQoL) and the Nottingham Health Profile (NHP) [7, 11, 33]. Sleep disorders are also assessed by the PsAID and the NHP instruments $[7,32]$. Thus this study confirms the global impact of PsA may be cross-culturally true and current questionnaires such as the PsAID may hold well as valid across cultures, but still need to be validated through quantitative studies.

Despite the substantial overlap of experiences of Brazilian and French PsA patients, there were important 
differences that legitimately require further research. Some aspects appeared more important for patients from Brazil than for patients from France. This includes sexual dysfunction, emotional impact of psoriasis (mainly embarrassment/shame due to skin lesions) and impact of prejudice on social and professional life.

A systematic review of articles reporting sexual dysfunction in PsA found that the severity of skin findings, the psychological effects of the condition, concerns of the sexual partner and side effects of medical treatments were associated with sexual disorders in PsA. This work emphasized that this type of symptomatology is frequently neglected in medical practice and also highlighted the lack of studies about the subject in Brazilian patients [34].

In the present work, the impact of prejudice due to skin lesions seemed more marked in Brazilians; categories such as, "discrimination at work", "discrimination in social life" and "embarrassment/shame" emerged only in the Brazilian sample. It is very probable, that in our work, the impact of prejudice due to skin disease was more intense in participants from Brazil because they had more severe psoriasis compared to subjects recruited in France. South of Brazil and Île-de-France, the two regions where patients were recruited, have similar climate, with four well defined seasons (contrasting with the North and Northeast regions of Brazil where high temperatures predominate throughout the year). The patients were recruited in both countries over a 2 -year period, meaning that interviews were conducted in both countries during all seasons. It seems less probable that the climate, sun exposure or clothing could be the responsible for the difference in the perceived impact of psoriasis referred by patients in Brazil and France.

The hypothesis that the impact of prejudice is higher in Brazil due to the lower educational level of the population in this country or due to cultural differences among countries is unsupported: a recent study with 1005 healthy French subjects showed that more than $60 \%$ of them recognized a lack of information about psoriasis and $50 \%$ of respondents showed discriminatory behavior toward psoriasis patients reflected by reluctance to maintain friendship ties/a relationship of friendliness (7.6\%), to have lunch or dinner with a person with visible manifestations $(17.9 \%)$, to give a kiss on the cheek in greeting (29.7\%), to shake hands (28.8\%) and to have sexual relations/intercourse (44.1\%) [35]. In that work, educational level was not associated with an increased prevalence of misconceptions and/or perceived discriminatory behaviors [35]. The impact of prejudice has also been previously recognized in another qualitative study which recruited European patients with PsA [36].

\section{Conclusion}

In conclusion, this study highlights the importance of assessing the impact of PsA on a national level, emphasizing the common cross-cultural impact of PsA but also exploring domains of interest for the Brazilian population which merit further studies.

\section{Abbreviations \\ CASPAR: Classification Criteria for Psoriatic Arthritis; GRAPPA: Group for Research and Assessment of Psoriasis and Psoriatic Arthritis; HAQ: Health Assessment Questionnaire; ICF: International Classification of Functioning, Disability and Health; NHP: Nottingham Health Profile; PsA: Psoriatic arthritis; PsAID: Psoriatic Arthritis Impact of Disease Questionnaire; PsAQoL: Psoriatic Arthritis Quality of Life; RA: Rheumatoid arthritis; SLE: Systemic lupus erythematosus; SLR: Systematic literature review}

\section{Acknowledgements}

We thanks Professor Odirlei André Monticielo from Universidade Federal do Rio Grande do Sul, Porto Alegre, Brazil and Professor Cláudia Diniz Lopes Marques from Universidade Federal de Pernambuco, Recife, Brazil for their suggestions to the manuscript.

\section{Funding}

The first author Penélope Palominos conducted the work with own resources. Professor Xavier received a research grant from National Council for Scientific and Technological Development (CNPq).

\section{Availability of data and materials}

The data used and analyzed during the current study are available from the corresponding author on reasonable request.

\section{Authors' contributions}

PEP, LG, WC, MdeW, NG, CLK, RMSC and RMX contributed to the conception and design of study. PEP, LG, SK, CLH, RMSC, ALDM, CLK contributed to acquisition of data. PEP, LG, RMX, WC, MdeW, NG, ALDM, CLH and SK contributed to analysis and interpretations of data. PEP and LG drafted the manuscript and all authors revised the manuscript critically for intellectual content. All authors read and approved the final manuscript.

\section{Ethics approval and consent to participate}

This study was performed in accordance with the ethical standards laid down in the 1964 Declaration of Helsinki and its later amendments. All patients gave their informed consent prior to their inclusion in the study. The study obtained ethical approval from the "Comitê de Ética do Hospital de Clínicas de Porto Alegre, Brazil", and the "Comité de Protection de Personnes- CPP Île-de-France VI, France".

\section{Consent for publication}

Not applicable.

\section{Competing interests}

Niti Goel is an employee of Quintiles IMS but declares no conflict of interest regarding this manuscript. The other authors have disclosed no conflict of interest.

\section{Publisher's Note}

Springer Nature remains neutral with regard to jurisdictional claims in published maps and institutional affiliations.

\section{Author details}

${ }^{1}$ Serviço de Reumatologia, Hospital de Clínicas de Porto Alegre, Ramiro Barcelos Street 2350, Porto Alegre Zip code 90035903, Brazil. 2Programa de Pós Graduação em Ciências Médicas, Universidade Federal do Rio Grande do Sul (UFRGS), Ramiro Barcelos 2400, Porto Alegre Zip code 90035903, Brazil. ${ }^{3}$ Institut Pierre Louis d'Epidémiologie et de Santé Publique. Pitié-Salpetrière Hospital, AP-HP, Rheumatology Department, Sorbonne Universités, UPMC Univ Paris 6, GRC-08, 83 Boulevard de l'Hôpital, 75013 Paris, France.

${ }^{4}$ Faculdade de Medicina, Departamento de Medicina Interna, Universidade Federal do Rio Grande do Sul (UFRGS), Ramiro Barcelos 2400, Porto Alegre 
Zip code 90035903, Brazil. ${ }^{5}$ Patient Research Partner, Group for Research and Assessment of Psoriasis and Psoriatic Arthritis (GRAPPA), University Health Network, Toronto Western Hospital, 399 Street Toronto, Bathurst, ON M5T 258, Canada. ${ }^{6}$ Department of Medical Humanities, Patient Research Partner, VU University Medical Centre, de Boelenlaan 1089a, 1081 HV Amsterdam, Netherlands. ${ }^{7}$ Patient Research Partner; Advisory Services, Quintiles; Division of Rheumatology, Duke University School of Medicine, Durham, North Carolina 27705, USA.

Received: 9 July 2018 Accepted: 8 October 2018 Published online: 22 October 2018

\section{References}

1. Tezel N, Yilmaz Tasdelen O, Bodur H, Gul U, Kulcu Cakmak S, Oguz ID, et al. Is the health-related quality of life and functional status of patients with psoriatic arthritis worse than that of patients with psoriasis alone? Int Rheum Dis. 2015;18:63-9.

2. Sokoll KB, Helliwell PS. Comparison of disability and quality of life in rheumatoid and psoriatic arthritis. J Rheumatol. 2001;28:1842-6.

3. Husted JA, Gladman DD, Farewell VT, Cook RJ. Health-related quality of life of patients with psoriatic arthritis: a comparison with patients with rheumatoid arthritis. Arthritis Rheum. 2001;45:151-8.

4. Kavanaugh A, Helliwell P, Ritchlin CT. Psoriatic arthritis and burden of disease: patient perspectives from the population-based multinational assessment of psoriasis and psoriatic arthritis (MAPP) survey. Rheumatol Ter. 2016;3:91-102.

5. Hagberg KW, Li L, Peng M, Shah K, Paris M, Jick S. Incidence rates of suicidal behaviors and treated depression in patients with and without psoriatic arthritis using the Clinical Practice Research Datalink. Mod Rheumatol. 2016;26:774-9.

6. Desthieux C, Granger B, Balanescu AR, Balint P, Braun J, Canete J, et al. Determinants of patient-physician discordance in global assessment in psoriatic arthritis: a multicenter European study. Arthritis Care Res (Hoboken). 2016. https://doi.org/10.1002/acr.23172 [Epub ahead of print].

7. Gossec L, de Wit M, Kiltz U, Braun J, Kalyoncu U, Scrivo R, et al. A patientderived and patient-reported outcome measure for assessing psoriatic arthritis: elaboration and preliminary validation of the Psoriatic Arthritis Impact of Disease (PsAID) questionnaire, a 13-country EULAR initiative. Ann Rheum Dis. 2014;73:1012-9.

8. Stam TA, Nell V, Mathis M, Coenen M, Aletaha D, Cieza A. Concepts important to patients with psoriatic arthritis are not adequately covered by standard measures of functioning. Arthritis Care Res. 2007;57:487-94.

9. Gudu T, Kiltz U, de Wit M, Kvien TK, Gossec L. Mapping the Effect of Psoriatic Arthritis Using the International Classification of Functioning, Disability and Health. J Rheumatol. 2017;44:193-200.

10. Torre-Alonso JC, Gratacós J, Rey-Rey JS, Valdazo de Diego JP, UrriticoecheaArana A, Daudén E, et al. Development and validation of a new instrument to measure health-related quality of life in patients with psoriatic arthritis: the VITACORA-19. J Rheumatol. 2014;41:2008-17.

11. Billing E, McKenna SP, Staun M, Lindqvist U. Adaptation of the Psoriatic Arthritis Quality of Life (PSAQoL) instrument for Sweden. Scand J Rheumatol. 2010;39:223-8.

12. McKenna SP, Doward LC, Whalley D, Tennant A, Emery P, Veale DJ. Development of the PSAQoL: a quality of life instrument specific to psoriatic arthritis. Ann Rheum Dis. 2004;63:162-9.

13. Wink F, Arends S, McKenna SP, Houtman PM, Brouwer E, Spoorenberg A. Validity and reliability of the Dutch adaptation of the psoriatic arthritis quality of life (PSAQoL) questionnaire. PLoS One. 2013;8:e55912.

14. Chisholm A, Pearce CJ, Chinoy H, Warren RB, Bundy C. Distress, misperceptions, poor coping and suicidal ideation in psoriatic arthritis: a qualitative study. Rheumatology (Oxford). 2016; [Epub ahead of print].

15. Stam T, Hieblinger R, Boström C, Mihai C, Birrell F, Thorstensson C, et al. Similar problem in the activities of daily living but different experience: a qualitative analysis in six rheumatic conditions and eight European countries. Musculoskelet Care. 2014;12:22-33.

16. Moverley AR, Vinall-Collier KA, Helliwell PS. It's not just the joints, it's the whole thing: qualitative analysis of patients's experience of flare in psoriatic arthritis. Rheumatology (Oxford). 2015;54:1448-53.

17. Kumar K, Gordon C, Barry R, Shaw K, Horne R, Raza K. 'It's like taking poison to kill poison but I have to get better': a qualitative study of beliefs about medicines in rheumatoid arthritis and systemic lupus erythematosus patients of south Asian origin. Lupus. 2011;20:837-44.
18. Sanderson T, Calnan M, Kumar K. The moral experience of illness and its impact on normalisation: examples from narratives with Punjabi women living with rheumatoid arthritis in the UK. Sociol Heal IIIn. 2015;37(8):1218-35.

19. Kumar K, Gordon C, Toescu V, Buckley CD, Horne R, Nightingale PG, et al. Beliefs about medicines in patients with rheumatoid arthritis and systemic lupus erythematosus: a comparison between patients of South Asian and White British origin. Rheumatology (Oxford). 2008;47:690-7.

20. Wen H, Ralph Schumacher H, Li X, Gu J, Ma L, Wei H, et al. Comparison of expectations of physicians and patients with rheumatoid arthritis for rheumatology clinic visits: a pilot, multicenter, international study. Int J Rheum Dis. 2012;15:380-9.

21. Ribeiro SL, Albuquerque EN, Bortoluzzo AB, Gonçalves $C R$, da Silva JA, Ximenes AC, et al. Quality of life in spondyloarthritis: analysis of a large Brazilian cohort. Rev Bras Reumatol. 2016;56:22-7.

22. da Costa IP, Bortoluzzo AB, Gonçalves CR, da Silva JA, Ximenes AC, Bértolo $M B$, et al. Evaluation of performance of BASDAI (Bath ankylosing spondylitis disease activity index) in Brazilian cohort of 1,492 patients with spondyloarthritis: data from the Brazilian registry of Spondyloarthritides (RBE). Rev Bras Reumatol. 2015;55:48-54.

23. Nota I, Drossaert $\mathrm{CH}$, Taal E, Vonkeman HE, van de Laar MA. Patient participation in decisions about disease modifying anti-rheumatic drugs: a cross-sectional survey. BMC Musculoskelet Disord. 2014;15:333.

24. Taylor W, Gladman D, Helliwell P, Marchesoni A, Mease P, Mielants H. Classification criteria for psoriatic arthritis: development of new criteria from a large international study. Arthritis Rheum. 2006;54:2665-73.

25. Depoy E, Gitlin LN. Introduction to research. St. Louis: Mosby; 1998.

26. Bruce B, Fries JF. The Stanford health assessment questionnaire (HAQ): a review of its history, issues, progress, and documentation. J Rheumatol. 2003:30:167-78

27. Szentpetery A, Johnson MAN, Ritchlin CT. GRAPPA Trainees Symposium 2013: A Report from the GRAPPA 2013 Annual Meeting. J Rheumatol. 2014:41:1200-5.

28. Crabtree B, Miller W. Doing qualitative research. London: SAGE; 1999. p. 406.

29. Hewlett S, Nicklin J, Bode C, Carmona L, Dures E, Engelbrecht M, et al. Translating patient reported outcome measures: methodological issues explored using cognitive interviewing with three rheumatoid arthritis measures in six European languages. Rheumatology (Oxford). 2016:55:1009-16.

30. Kalyoncu U, Ogdie A, Campbell W, Bingham CO 3rd, de Wit M, Gladman $D D$, et al. Systematic literature review of domains assessed in psoriatic arthritis to inform the update of the psoriatic arthritis core domain set. RMD Open. 2016:2:e000217.

31. Palominos PE, Gaujoux-Viala C, Fautrel B, Dougados M, Gossec L. Clinical outcomes in psoriatic arthritis: A systematic literature review. Arthritis Care Res (Hoboken). 2012;64:397-406.

32. Orbai AM, de Wit M, Mease P, Shea JA, Gossec L, Leung YY, et al. International patient and physician consensus on a psoriatic arthritis core outcome set for clinical trials. Ann Rheum Dis. 2016. https://doi.org/10.1136/annrheumdis-2016210242 [Epub ahead of print].

33. Hunt SM, McKenna SP, MEwen J, Backtt EM, Williams J, Papp E. A quantitative approach to perceived health status: a validation study. J Epidemiol Community Health. 1980;34:281-6.

34. Kurizky PS, Mota LM. Sexual dysfunction in patients with psoriasis and psoriatic arthritis - a systematic review. Rev Bras Reumatol. 2012;52:943-8.

35. Halioua B, Sid-Mohand D, Roussel ME, Maury-le-Breton A, de Fontaubert A, Stalder JF. Extent of misconceptions, negative prejudices and discriminatory behaviour to psoriasis patients in France. J Eur Acad Dermatol Venereol. 2016;30:650-4.

36. Uttjek M, Nygren L, Stenberg B, Dufåker M. Marked by visibility of psoriasis in everyday life. Qual Health Res. 2007;17:364-72. 